\title{
Assessing Manual and Online Course Registration in Nigeria Tertiary Institutions
}

\author{
Oladunjoye Patrick ${ }^{1, *} \&$ Omemu Felix ${ }^{1}$ \\ ${ }^{1}$ Educational Foundations Department, Niger Delta University, Wilberforce Island, Bayelsa State, Nigeria \\ *Corresponding author: Educational Foundations Department, Niger Delta University, Wilberforce Island, Bayelsa \\ State, Nigeria. Tel: 234-803-548-7209. E-mail: meetpatola@yahoo.com
}

Received: September 24, 2013

Accepted: November 4, 2013

Online Published: November 13, 2013

doi:10.5430/wje.v3n6p8

URL: http://dx.doi.org/10.5430/wje.v3n6p8

\begin{abstract}
The study is aimed at assessing the perceptions of male and female students on manual and online course registration systems in tertiary institutions in Nigeria. One research question was formulated to guide the study. A questionnaire containing 20 items on assessing the perceptions of students on manual and online course registration was drawn. This was validated by experts in test and evaluation in Niger Delta University, Wilberforce Island, Bayelsa State, Nigeria. The instrument was tested for reliability using the test re-test method. The data collected was analysed using the Pearson Product Moment Correlation Coefficient and it was established at 0.88 which shows that the instrument is reliable - 750 male and 750 female students were randomly selected from 3 notable Universities in the 3 regions in Nigeria. The data collected from the administered questionnaire was analysed using the t-test statistics and mean $(\bar{x})$ scores as well as standard Deviation (SD). It was discovered that there is no significant difference in the perceptions of male and female students on manual and online course registration systems. The respondents hold that online registration saves time, it is cost effective, information can easily be retrieved, high storage capacity, easily accessible and it is in line with the digital age. The manual registration only encourages mutual cooperation among students and errors made can be easily corrected. Suggestions were made for better improvement of online course registration system.
\end{abstract}

Keywords: online, manual; web; automated; download

\section{Introduction}

In all tertiary institutions, the academic curriculum specifies that there are specific number of courses a student is required to offer. This demand is to certify the conditions required by every student to graduate or deem to have completed the course of study. The activity of course registration is vital and procedural. A bonafide student is expected to register for a particular number of workload for each semester/session. Some of the courses may be core or elective depending on the academic policy of the institution. Course registrations are often verified and certified before the student is eligible to attend classes or sit for the examination.

Up till 1990, registration of courses was done manually in virtually all tertiary institutions in Nigeria. Students collect course registration forms from either the registry, departmental offices or faculty offices. They fill in the courses to be offered for that semester/session and move from one office to the other for the signing of such forms.

Ajayi (2004) noted that this method was cumbersome and time wasting. While lectures are on, students are often seen parading course registration forms from one office to another. These forms could be torned or destroyed by the rain even before the completion of the exercise. The long ques waiting for the signing or collection of course registration forms could be very frustrating to students. Students with various academic problems often take advantage of the slightest chaos on campus to burn down papers in the various offices. It requires a large office space to archieve these forms and in most cases it is very difficult to retrieve information from them. They are susceptible to rain, moisture, and rodents.

Akinde (2004) however stated that students have a better orientation of their college when they actively involve themselves in manual course registration. They identify the offices easily and even know the names of some of their 
lecturers and officers in the college or University. They develop a good inter-personal relationship with their superior. In the process of looking for the offices to sign the course forms, students are bound to interact with each other, they develop better understanding of their environment, learn how to be patient and develop good communication skills. Errors can easily be detected and corrected manually. If properly kept and preserved, it could be a source of reference from time to time. It is not exposed to virus attack except rodents and file cannot be corrupted except it is willfully altered. Oni (2011) holds that manual course registration is part of the orientation programme for every student. It will enable them have a better understanding of their environment.

The idea of online registration is in line with the world's latest trend of information technology. The internet as a major component of the information technology has influenced the day to day administration of most organizations. The computer as a major instrument can maintain accurate and consistent database. Chaoes (2006) noted that the computer has the advantage of automated calculation and retrieval capabilities. The computer can be employed in the automation of all data processing activities such as data sourcing, data capture, storage and retrieval. Adeniyi (2012) noted that the computer is the modern technology to enhance efficiency.

The computer has taken over the clerical complications that is noted among most organizations. The database provides the module for updating, insertion and refreshing data in such a simple and easy way that large quantity of data can be handled with ease. The computer system permit the same amount of work to be done at a lower cost and it saves a lot of time. Most database programmes are easily used in recent organizations. The facilities in web technology is capable of sorting, handling and sharing various qualities of data and it results to the development of special high-capacity and fast computers called servers. These servers are specially equipped for network and database services.

The online registration system allows students, through the internet to register, drop or add courses within the registration period. The students are expected to go into a cybercafe or any available internet facility and log in to the school web site and register courses for the semester/session. They submit at the end of such registration and all these are collated into the registration file which can easily be assessed by the management. Such registrations are often online within a period of time. As soon as such sites are blocked or closed, registration becomes impossible and such defaulting students may have to suspend studies for that semester/session.

Nigeria is a developing nation. Most of the students in the various Universities in the country are products of rural secondary schools where they had little or no access to electricity and internet facilities. Akintoye (2008) noted that in virtually all institutions of higher learning in Nigeria, course registrations are often contracted out to vendors who liter the campus with assorted laptops and modems for brisk business. As a result of the scramble, serious errors are made such as wrong spellings of names, irregular entries, etc. The ideal situation is that students are expected to register online themselves at their convenience and even at home. Adetoye (2012) added that in a developing economy, over indulgence in modern technology could make many people jobless.

Computer education has remained a problem in Nigeria as noted by Adeojo (2002). In the private nursery; primary, and secondary schools, computer education is used as a tool for advertisement but it is pure aesthetic with the aim of getting customers. At the public schools, emphasis is placed on theory with little or no emphasis on the practical aspects of the subject. Apart from the fact that there are very few teachers, the facilities needed for computer education are completely absent especially at the rural areas as noted by Onah (2006). Students with such poor background will find it difficult to embrace online course registration.

The possession of a laptop or computer set is a matter of social status in Nigeria. The level of poverty of most parents cannot afford them the opportunity of buying even books for their wards talk less of a laptop (Adeotun 2006) it is expected that the government was suppose to supply computers to schools. Most schools are located where there is no assess to electricity. Students from such indigent homes find it difficult to embrace modern technology easily.

Most students have to travel far distances to the nearest available cybercafé to register their courses online especially when there is a closing date. Apart from the risk involved in such journeys especially those in riverine areas. Most operators of such cybercafés are not abreast of the university guidelines on course registration and most students cannot also operate the computer system so it becomes a case of a blind man leading a blind man.

Onyewuenyi (2002) stated that the computer can only process the information that is imputed into the system. So, it will only respond to the data inputed. If the data is wrong, the outcome may also be wrong hence the axiom, 'Garbage in Garbage out'. Ones error is made it become very difficult to correct unlike the manual forms which can be easily erased or corrected. Several students have to carryover some courses as a result of errors noticed in the online course registration. 
The essence of online registration is the ease of collating data and retrieving the information anytime the need may arise. This can only be made possible where there is a steady source of power. Despite the effort made by the Federal Government on the improvement of power generation in the country, there are still several institutions of higher learning in Nigeria that depend on generating sets for power (Akinde 2002). Where the systems crash as a result of this epileptic power supply, the information may be lost especially when there is a virus attack on the files or no backup.

Online registration is a recent technology in school administration. Before the advent of on-line registration, students were faced with a monotonous task of manual registration of courses where students were faced with all manner of intimidation and wrong attitude from staff who are supposed to sign such forms. This manual method of students carrying forms all over the campus exposed the female students to all manners of sexual harassment and extortion form students by some clerical staff. Ojo (2013) noted that apart from the fact that there are several reported cases of sexual harassment among students and lecturers, the clerical staff and other administrative staff often use the dealine placed on submission of course forms to harass and extort money. Ajayi (2004) stated that on-line registration has put an end to all manners of complaints by students about the non-challent attitude of some staff in signing course forms.

The Nigerian academic calendar is most unpredictable. Most academic sessions are marked with various industrial actions such that lecturers or non academic staff stay out of office for several weeks or months. As a result of such strike actions, it becomes impossible for students to register their courses within the stipulated time. This often result to rush and in the process so many course forms are misplaced. With online, registration could still be on even when the schools and colleges are on strike. It is more convenient especially for those who live in urban centres with all the internet facilities present.

On-line course registration allows quickers response at noted by Ademilokun (2004). A well designed student record system allows for timely retrieval of the needed information concerning any student. With just a push of a button, the needed information that could guide decision making are easily retrieved.

Chaoes (2006) noted that a well conceived and implemented automated student record system can reduce the cost of handling the paper work associated with record keeping. The needed information are either stored in the harddrives or other devices such as the flash drive, compact disc, etc which has the capacity to store a large number of files. Record keeping has remained major challenge in manual registration. There are inadequate office spaces to house the large number of student files.

An effective automated student record system provide the information required on request easily Connolly and Begg (2004) maintained that the online registration provides efficient information about students which are securely stored in the computer system and can be retrieved with ease.

Data is essential in planning. The number of students that have registered for a particular course will assist the timetable planners to know the type of classroom that could be suitable for such lectures. It may also help to determine the number of lecturers needed. Data quality is basic to a well-designed student record system. With the online registration, Onyewuenyi (2002) noted that there is ease of calculation instead of manual calculations. The automated system gives accurate data of the number of entries made and can even distribute the data into various stratas such as departments, gender, etc. the quality of data generated can easily aid the educational planners.

The individual students, school authorities and the government have major roles to play in the issue of manual or online course registration. Students are expected to master the course registration procedure effectively as noted by Amadieochi (2001). This will help to reduce the various errors noted with most of the online course registrations. It is expected that the school authorities are to create necessary avenues needed for students to learn the procedures and make such information easily accessible to students and that government should promote the teaching of computer education and encourage rural areas to embrace modern technology by providing uninterrupted power supply to her citizenry (Akinde, 2004).

\section{Purpose of the Study}

In most developing nations, the modern technology has not been fully embraced. Taiwo (2012) noted that despite the fact that the world is fast becoming a global village as a result of the modern information and communication technologies, some countries especially the developing nations are still struggling to meet up with this modern challenge. 
The purpose of this study therefore is to assess manual and online course registration as perceived by students. The study is aimed at determining whether students prefer the online course registration to the manual or vice versa.

\section{Statement of Problem}

In line with the recent trend of population explosion and the high demand for tertiary education in Nigeria, there is the need to promote efficiency and accuracy especially in data gathering. The course registration is an essential academic routine for every student. If this important routine is done manually or electronically, what is the perception of the Nigerian student concerning the manual and online registrations. The manual course registration entails the manual handling of course registration whereby students collect course forms and fill them manually while the online registration involves the use of the internet to download and upload information concerning courses to be registered. Which of these two methods will they prefer?

\section{Hypothesis}

This hypothesizes was formulated to guide the study:

$\mathrm{Ho}_{1}$ : There is no significant difference in the perceptions of students on manual and on-line course registration in tertiary institutions.

\section{Methods}

The study is a descriptive survey designed to examine the perceptions of students on manual and on-line course registration in tertiary institutions in Nigeria. It covered 3 major universities in the 3 regions of Nigeria. Northern region - Ahmadu Bello University, Zaria, Eastern region University of Nigeria, Nsukka and Western region University of Ibadan. 500 students were randomly selected from each university A total of 750 male and 750 female students were selected. They are expected to be students who are exposed to computer studies but not minding their level of computer literacy. A sample of 1500 students was randomly selected from the 3 universities using the stratified random sampling technique. The faculties and departments were randomly selected. Names of students from the selected departments were stratified into groups and the numbers were randomly selected. The age of the students selected for study are students from 17 to 30 years. Equal ratio of boys and girls were also selected -750 boys and girls. Only undergraduate students were used in the study; 100 level to 400 levels.

A questionnaire containing 20 items on assessing manual and on-line course registration was designed by the researcher. The instrument was validated by 3 experts in test and evaluations of the Niger Delta University, Wilberforce Island, Bayelsa State. The instrument was further subjected to a reliability test using the test- re-test method. 20 respondents who were not originally included in the sample size were used. The data collected was analysed using he Pearson Product Moment Correlation Coefficient and was established at 0.83 which shows that the instrument is reliable.

The questionnaire was divided into two sections. Section A sought information about the personal data of the respondent while section $\mathrm{B}$ contained the 20 items assessing the perceptions of student concerning manual and online course registration systems. The questionnaires were personally administered by the researcher and 10 research assistants. The filled questionnaires were collected on the spot hence the $100 \%$ rate of return.

The data was analysed using the t-test statistics and their relevant descriptive statistics.

\section{Results}

Based on the anlaysis of the data obtained from the study, result obtained from table 1 shows that manual course registration system is very favourable in the area of correction of information as perceived by the students with a $\bar{x}$ score of 2.73. The respondents also favoured the manual course registration as they believe that it is not prone to errors like the online course. 
Table 1: Response on Student Perceptions on Manual and Online Course Registration Systems

\begin{tabular}{llllllll}
\hline & & \multicolumn{3}{c}{ Manual Registration } & \multicolumn{3}{c}{ On-line Registration } \\
\hline & \multicolumn{1}{c}{ Items } & $\bar{x}$ & $\mathrm{SD}$ & Decision & $\bar{x}$ & $\mathrm{SD}$ & Decision \\
\hline 1 & Saves time & 1.34 & 0.46 & $\mathrm{NF}$ & 2.7 & 1.3 & $\mathrm{~F}$ \\
2 & Cost effective & 1.28 & 0.31 & $\mathrm{NF}$ & 3.2 & 1.8 & $\mathrm{~F}$ \\
3 & Ease of competition & 1.72 & 0.52 & $\mathrm{NF}$ & 2.8 & 1.4 & $\mathrm{~F}$ \\
4 & Retrieval of information & 1.81 & 0.61 & $\mathrm{NF}$ & 2.9 & $1 . .5$ & $\mathrm{~F}$ \\
5 & Correction of information & 2.73 & 1.32 & $\mathrm{~F}$ & 1.28 & 0.31 & $\mathrm{NF}$ \\
6 & Storage & 1.33 & 0.45 & $\mathrm{NF}$ & 2.91 & 1.5 & $\mathrm{~F}$ \\
7 & Accessibility & 1.42 & 0.48 & $\mathrm{NF}$ & 2.72 & 1.3 & $\mathrm{~F}$ \\
8 & Prone to errors & 2.81 & 1.4 & $\mathrm{~F}$ & 1.81 & 0.61 & $\mathrm{NF}$ \\
9 & Mutual cooperation & 2.93 & 1.5 & $\mathrm{~F}$ & 1.72 & 0.52 & $\mathrm{NF}$ \\
10 & Digitalization & 1.28 & 0.31 & $\mathrm{NF}$ & 2.90 & 1.5 & $\mathrm{~F}$ \\
& & & & & & &
\end{tabular}

$$
\begin{aligned}
& \text { Decision Rule }=2.5+\quad=\quad \text { favourable } \\
& 2.4-=\text { Not favourable } \\
& \underline{\bar{x}} \\
& \mathrm{~F}=\text { Favourable NF }=\text { Not favourable }
\end{aligned}
$$

The respondents perceived that the online course registration is more favourable in saving time $(\bar{x}=2.7)$, it is cost effective $(\bar{x}=3.2)$, there is ease of completion $(\bar{x}=2.8)$, information can be easily retrieved $(\bar{x}=2.9)$ information is easily accessible ( $\bar{x}=2.72)$, and it is in line with the current wave of digitalization $(\bar{x}=2.90)$. The results are in line with the view and findings of Ademillokun (2004), Chao (2006) Connolly and Begg (2004).

The result in table 2 also shows that there is no significant difference in the perceptions of students concerning manual and online course registration systems. All the respondents share the same view concerning manual and online registration. The calculated $t=0.93$ and less than the critical $t$ value of 1.96 . This shows that there is no significant difference in the perceptions the respondents concerning manual and online course registration.

Table 2: $\mathrm{t}$ - Test Analysis of the Significant Difference between Manual and Online Course Registration Systems

\begin{tabular}{llllllll}
\hline Variables & $\mathrm{N}$ & $\bar{x}$ & $\mathrm{SD}$ & $\mathrm{Df}$ & + cal & T crit & Remark \\
\hline Male students & 750 & 12.47 & 1.37 & & & & \\
Female students & 750 & 11.08 & 1.21 & 1498 & 0.93 & 1.96 & Not significant \\
\hline
\end{tabular}

\section{Discussion}

From the analysis of the results in tables 1 and 2, the manual; course registration waste a lot of time as noted by Ademilokun (2004) and it is not cost effective; a lot of money is needed to print out forms to be distributed to students. It is easier to fill in courses using the online registration than completing course forms manually which must also be signed by some designated staff. It is easier to retrieve information as noted by Chao (2006) using the online registration than manual which may be cumberson, though it is easier to correct any mistake made in the manual registration than the online registration once it is submitted or entered. Large information concerning all the students are simply stored in a flash or any electronic device as noted by Connolly and Begg (2004). The information are easily accessible using the online but it will take a lot of energy to scout for a particular student's form using the manual method. Although, Onyewueny, (2002) noted that the electronic or online registration is prone to errors especially by students who are not computer literate as supported by Ajayi (2004) the result is in line with the digitalization era which is the current wave of technology worldwide. However, manual registration enhance mutual cooperation among students as they move from office to office to sign their course forms as supported by Ojo (2013). 


\section{Findings}

Based on the analysis of data and results derived from the data, the following findings were made:

- There is no significant difference in the perceptions of students concerning manual and online course registration systems.

- The online registration saves a lot of time.

- Online registration is cost effective

- There is ease of completion of form using the online registration method

- Information can easily be retrieved using the online registration

- Wrong information or errors made cannot be easily corrected with the online registration.

- Data can be stored more easily and conveniently with the online registration.

- Information can be easily accessed with the online registration

- Students are prone to making mistakes with the online registration.

- The manual course registration encourages mutual cooperation among students.

- The online registration is in line with the modern digitalization of information

\section{Conclusion}

Course registration is an essential aspect of the requirement expected of every student to be qualified to participate in the examinations required for that semester or session. Although there seems to be a uniform guideline for course registrations as stipulated by the work load requirements per semester of session as laid down by the minimum standards of the Nigerian Universities Commission for all Universities, National Commission for Colleges of Education for the colleges of education and National Board for Technical Education for polytechnics. There are stipulated numbers of credit units a student is eligible to register for a semester/session. The process of registration may differ from one tertiary institution to another. While some institutions may favour the online registration, some still adopt the manual registration system. This study attempts to assess the perceptions of students concerning the manual and online registration. It was discovered that virtually all the respondents in respective of gender or level of study favour the online course registration system. It is believed to be easier, cost effective, saves time, convenient, easy retrieval of information among several other benefits.

The manual course registration is said to be outdated and not in line with the modern digital age apart from other several set backs. Despite the fact that manual course registration encourages manual cooperation among students and errors made can be easily corrected if detected, the manual course registration is not favourable to students, as perceived by the respondents.

\section{Recommendations}

Based on the findings, the following recommendations are made

- Online course registration should be encouraged by all tertiary schools administration in Nigeria. The online course registration is cheaper and in line with modern technology. Students should be encouraged to embrace modern technology.

- Computer education should be made compulsory at all levels. Even as a developing nation with problem of epileptic power supply and high level of poverty. Computer studies must be made compulsory in schools.

- Emphasis should be placed specially on the practical aspects of computer education. The general course on computer studies in most Universities is theoretical based. Emphasis should be on practicals.

- Urban and rural schools should be provided with sufficient computers by the government. The rural schools are often neglected. Teachers even reject posting to such rural schools. Government should made such schools attractive for teachers.

- Special orientation programmes should be organized by the tertiary school administration to equip students and staff with the online course registration procedure at the point of admission. Students should be given a special orientation about online course registration. 


\section{References}

Ademilokun, P (2004). School Routine. Ilesha, Ilesanmi Press Ltd.

Adeniyi, P. (2012). Modern technology: Issues. Ilesha: Ilesanmi Printing Press.

Adeojo, F. (2002). Internet Rules. Owerri, African Educational Services.

Adeotun, P.A. (2006). School Administration. Ibadan, Heineman Pub.

Adetoye, F. (2012). Introduction to Computer studies. Jos: Hilltop Publishing Coorporation.

Ajani, S.L. (2004). Oracle database. Ibadan, Spectrum books Ltd.

Ajayi, S.O. (2004). Information Technology. Ibadan Spectrum Books Ltd.

Akinde, F. (2004). Website Design Technology. Jos, Rolk Print Pub.

Akinde, S. (2002). Database System Concepts. London, Mcgraw Hill.

Akintoye, L.M. (2008). Computer Studies. Onitsha, Spiriton Publications

Amadiwochi, A.L. (2001). Modern Scientific Management Information System, Portharcourt, Rodi Printing and Publishing CO.

Chaoes, L. (2006). Database Development and Management. London, Auerbach Ltd.

Connolly T.M., \& Begg, C.E. (2004). Database System; A Practical approach to design, implementation and management, USA, Addison Wesley.

Ojo C.S. (2013). University administration. Lagos; Joja Educational Books Ltd.

Onah, M. (2006). Computer Studies - Problems and Prospects. Enugu; Fourth Dimension Pub. Co. Ltd.

Oni, S. (2011). Orientation Programme for new Intakes. Enugu: Sally Publishing Company.

Onyewuenyi, R.N. (2002). Micros Computer Studies for beginners. Onitsha, Spiriton Pub.

Taiwo, F.A. (2012). The developing nations. Ibadan: Spectrum books limited. 